\title{
Keratinocyte growth factor protects against Clara cell injury induced by naphthalene
}

\author{
A.Ö. Yildirim*^, M. Veith*, ${ }^{*}$, T. Rausch*, B. Müller*, P. Kilb*, L.S. Van Winkle ${ }^{\#}$ \\ and H. Fehrenbach*
}

ABSTRACT: Airway epithelial cells are exposed to environmental toxicants that result in airway injury. Naphthalene (NA) causes site-selective damage to Clara cells in mouse distal airways. $\mathrm{N}$ terminally truncated recombinant human keratinocyte growth factor ( $\mathrm{N}$ 23-KGF) protects against acute lung injury. The present study investigated whether or not $\triangle$ N23-KGF protects against NAinduced acute Clara cell damage by measuring airway responses specifically and in order to identify underlying molecular mechanisms.

Mice were treated with $\triangle$ N23-KGF or PBS $33 \mathrm{~h}$ prior to injection of $200 \mathrm{mg} \cdot \mathrm{kg}$ body weight ${ }^{-1} \mathrm{NA}$. Lung function was analysed by head-out body plethysmography. Distal airways isolated by microdissection were assessed for cell permeability using ethidium homodimer-1. Immunohistochemistry of Clara cell-specific protein in conjunction with a physical dissector was used to quantify Clara cell numbers. RNA was isolated from frozen airways in order to analyse gene expression using quantitative RT-PCR.

$\Delta$ N23-KGF prevented NA-induced airflow limitation and Clara cell permeability, and resulted in twice as many Clara cells compared with PBS pre-treatment. $\triangle$ N23-KGF-pre-treated mice exhibited increased expression of proliferating cell nuclear antigen mRNA. Cytochrome $\mathbf{P}_{450}$ isoform $2 \mathrm{~F} 2$, which converts NA into its toxic metabolite, was reduced by $\sim 50 \%$.

The present results demonstrate that pre-treatment with $\mathrm{N}$-terminally truncated recombinant human keratinocyte growth factor protects against naphthalene-induced injury. This suggests that $\mathrm{N}$-terminally truncated recombinant human keratinocyte growth factor exerts its beneficial effect through a decrease in the expression of cytochrome $P_{450}$ isoform $2 F 2$.

KEYWORDS: Airway epithelial injury, cytochrome $\mathbf{P}_{450}$, keratinocyte growth factor, naphthalene, secretoglobin

$\Delta$ irway injury, repair and remodelling are implicated in the pathogenesis of diverse lung diseases, such as asthma, chronic obstructive pulmonary disease and lung cancer [1]. Among the many agents that cause lung injury, hazardous air pollutants have chronic adverse effects on lung function [2], and are likely to contribute significantly to morbidity and mortality in humans [3]. The airway epithelium is composed of a few major cell types, ciliated epithelial cells, Clara cells, neuroepithelial cells, basal cells, mucous cells and serous cells [4]. It provides a selectively permeable barrier between the internal tissues and the potentially hazardous agents entering the body via the airways. In particular, the distal airways are exposed at high levels to various environmental oxidants, which may lead to epithelial injury in this specific region [5].
Naphthalene (NA), a harmful environmental toxin, can be found in ambient air, ground water and cigarette smoke and is produced by combustion [6]. NA is used as feedstock in various chemical industrial processes and was suggested to pose a problem in the workplaces of various industries [7]. NA, which has been found to be the most abundant polycyclic aromatic hydrocarbon in sidestream cigarette smoke [8], selectively injures nonciliated Clara cells of the conducting airways. The toxicity of NA requires metabolic activation, which is catalysed by cytochrome $\mathrm{P}_{450}$ monooxygenases [9]. In addition to their general secretory role [10], mouse Clara cells are the primary cellular site of cytochrome $\mathrm{P}_{450}$ monooxygenase isoform 2F2 (CYP2F2) [11], an enzyme with both high catalytic activity for NA and great abundance in the mouse airway [12].
AFFILIATIONS

${ }^{*}$ Clinical Research Group "Chronic Airway Diseases", Medical Faculty, Philipps University of Marburg, Marburg, Germany, and

\#Dept of Anatomy, Physiology and Cell Biology, School of Veterinary Medicine and Center for Health and the Environment, University of California, Davis, CA, USA.

"Both authors contributed equally to this study.

\section{CORRESPONDENCE}

A.Ö. Yildirim, Clinical Research Group "Chronic Airway Diseases", Medical Faculty, Philipps University Marburg, Hans-Meerwein Str.1, 35043 Marburg, Germany. Fax: 4964212866095

E-mail: ayildiri@med.

uni-marburg.de

Received:

November 192007

Accepted after revision:

March 182008

SUPPORT STATEMENT

This study was supported, in part, by a grant from the German Research

Foundation (Bonn, Germany) to

H. Fehrenbach (FE287/8-1).

L.S. Van Winkle's role in this research was supported by grants from the National Institute of Health (Bethesda, MD, USA; ES012720) and the State of California's TobaccoRelated Diseases Program (Oakland, CA, USA; 14RT0132). The University of California (Davis, CA, USA) is a National Institute of Environmental Health Sciences Center for Environmental Health Sciences (ES05707) and supported core facilities used in sections of this study.

STATEMENT OF INTEREST

None declared. 
Therefore, murine Clara cells are more susceptible to NAinduced cytotoxic injury than other types of airway epithelial cell [13].

Keratinocyte growth factor (KGF), also known as fibroblast growth factor (FGF) 7, has been identified as an important paracrine mediator of proliferation, migration and differentiation of alveolar epithelial type II cells [14]. KGF binds specifically to the KGF receptor, a splice variant of FGF receptor 2 (isoform IIIb), which is expressed by epithelial cells [15]. In animal studies, KGF reduces alveolar injury and mortality in rat and/or mouse models of acute lung injury to the gas exchange area [14]. Knowledge is much more limited with regard to the role of KGF in acute airway epithelial injury and repair. KGF was demonstrated to be important for the detoxification of reactive oxygen species [16], and to enhance proliferation in airway cells [17]. Administration of KGF was shown to protect against radiation-induced increases in airway epithelial barrier permeability [18], exert protective effects against oxidant injury [19] and limit allergen-induced alterations in airway epithelial integrity [20]. Furthermore, KGF accelerated epithelial wound closure in bronchial epithelial cells cultured in vitro [21], and studies in the heterotopic tracheal transplant model revealed that KGF enhanced airway epithelial repair involving both local resident progenitor epithelial cells and the mobilisation and engraftment of circulating epithelial progenitor cells [22].

Despite the important function of KGF in the lung, the role of KGF in the airways is not well understood. Microarray analyses of human primary bronchial epithelial cells incubated with KGF in vitro revealed a decrease in the expres-sion of CYP2F1 mRNA [23]. Human CYP2F1 exhibits 80\% homology with mouse CYP2F2 and is also expressed in the respiratory tract [24]. Therefore, it was hypothesised that pre-treatment of lungs with $\mathrm{N}$-terminally truncated recombinant human KGF ( $\triangle$ N23-KGF; palifermin), which is characterised by enhanced protein stability [25], protects against NA-induced acute Clara cell damage of the murine distal airways. In order to address this question, four experimental approaches were used: 1) distal airways from mice pre-treated with $\triangle \mathrm{N} 23-\mathrm{KGF}$ or PBS were isolated by microdissection [26] and analysed for cell membrane integrity, cell proliferation and Clara cell number following NA-induced injury; 2) serial noninvasive lung function analysis was performed in unanaesthetised mice by means of head-out body plethysmography [27] in order to assess the functional relevance of NA-induced acute airway injury and the potential protective effect of $\Delta \mathrm{N} 23-\mathrm{KGF}$ at the organ level; 3) the effect of KGF treatment on mRNA expression of CYP2F2, which catalyses the conversion of NA into its cytotoxic $1 R, 2 S$-oxide [12], was analysed in microdissected distal airways, as well as in Clara cell-enriched pulmonary epithelial cells isolated from mouse lungs; and 4) mice were therapeutically treated with $\triangle \mathrm{N} 23-\mathrm{KGF}$ at different time-points following the injection of NA in order to test the hypothesis that the protective effect of KGF treatment was dependent upon the presence of Clara cells.

\section{MATERIALS AND METHODS \\ Animals}

Pathogen-free male C57BL/6 mice (Harlan Winkelmann, Hanover, Germany) weighing 25-29 g and aged 8-10 weeks were used in all of the experiments. The animals were allowed free access to food and water. All of the animals were euthanised by an over-dose of sodium pentobarbital $\left(100 \mathrm{mg} \cdot \mathrm{kg}\right.$ body weight ${ }^{-1}$ intraperitoneally) followed by exsanguination. All animal procedures were performed according to the guidelines of good animal experimental practice of the Philipps University of Marburg (Marburg, Germany) and approved by the local authorities for animal experiments.

\section{Application of growth factor}

Mice were anaesthetised by short-term inhalation of isoflurane (Abbot, Wiesbaden, Germany). Each mouse received a single bolus of $10 \mathrm{mg} \cdot \mathrm{kg}$ body weight $^{-1} \Delta \mathrm{N} 23-\mathrm{KGF}$ (Amgen, Thousand Oaks, CA, USA) by oropharyngeal aspiration or an equivalent volume of PBS $(80 \mu \mathrm{L})$. This dose was found to induce the maximal proliferative response of alveolar epithelial type II cells in mice [28]. Treatment was performed $33 \mathrm{~h}$ prior to intraperitoneal injection of NA or corn oil.

\section{Application of NA}

NA was purchased from Fisher (Aschaffenburg, Germany) and dissolved in corn oil. C57BL/6 mice were injected with $200 \mathrm{mg} \cdot \mathrm{kg}$ body weight ${ }^{-1} \mathrm{NA}$ or corn oil alone as vehicular control and were sacrificed $12 \mathrm{~h}$ later. This time-point was chosen because experiments studying the kinetics of NAinduced acute airway injury revealed that, after $12 \mathrm{~h}$, Clara cells were already damaged but exfoliation was still incomplete, whereas complete exfoliation was observed $24 \mathrm{~h}$ after injection of NA (see online supplementary material). Distal airways were microdissected and processed for histological analysis. In order to evaluate the protective effect of $\Delta$ N23KGF, mice were pre-treated with $\Delta$ N23-KGF or PBS. Mice were sacrificed $12 \mathrm{~h}$ after NA treatment and distal airways were isolated by microdissection. In order to exclude effects of circadian rhythm, all applications were performed between 08:00 and 10:00 h.

In order to evaluate whether the effect of $\Delta \mathrm{N} 23-\mathrm{KGF}$ is primarily related to Clara cells, mice were treated with $200 \mathrm{mg} \cdot \mathrm{kg}$ body weight ${ }^{-1} \mathrm{NA} 2$ or $24 \mathrm{~h}$ prior to oropharyngeal aspiration of $10 \mathrm{mg} \cdot \mathrm{kg}$ body weight $^{-1} \Delta \mathrm{N} 23-\mathrm{KGF}$. Animals were sacrificed 5 days later.

\section{Tissue preparation and microdissection}

Procedures for the microdissection of defined airway generations have been described in detail previously [26]. Briefly, after sacrifice by cervical dislocation, the trachea was exposed and cannulated. The lungs were removed from the thorax and inflated with 1\% low melting-point agarose (Sigma-Aldrich, Munich, Germany) dissolved in $2 \times$ Waymouth's medium (Sigma-Aldrich) and incubated in Ham's F-12 nutrient mixture (Sigma-Aldrich) for $30 \mathrm{~min}$ on ice in order to allow the agarose to solidify. Distal airways were isolated from the left lung of each mouse.

\section{Assessment of cell permeability}

For cell permeability studies, microdissected airways were incubated with ethidium homodimer (EH)-1 (Sigma-Aldrich) in Ham's F-12 nutrient mixture for $20 \mathrm{~min}$ at $37^{\circ} \mathrm{C}$ in order to label the nuclei of any cells with permeable membranes, as described previously [29]. Airways were washed three times with F-12 medium at $37^{\circ} \mathrm{C}$ to remove unincorporated $\mathrm{EH}-1$ and 
fixed with 330 mOsm Karnovsky's fixative. Airways were stored in fixative in the dark until embedment into glycol methacrylate (Technovit 7100; Heraeus Kulzer, Wehrheim, Germany). Embedded airways were cut into $1-\mu \mathrm{m}$ thick sections. A water soluble nonfluorescing mounting medium, Fluoromount-G ${ }^{\mathrm{TM}}$ (Southern Biotechnology, Birmingham, AL, USA), was used.

For imaging, an epifluorescent microscope (Olympus, Tokyo, Japan) equipped with a wide-band ultraviolet (UV) fluorescence excitation-emission filter set was used. As there is a phase shift in the wide-band UV excitation-emission filter set, the tissue autofluoresces green and EH-1-positive nuclei pinkish-white.

\section{Airway fixation}

For quantitative morphological analysis, at least four microdissected distal airways from each mouse $(n=3)$ were fixed in $1 \%$ phosphate-buffered formalin, orientated such that the resulting sections were normal to the longitudinal axis of the airways, and embedded in paraffin. For RNA isolation and subsequent gene expression analyses, three microdissected airways from each mouse $(n=3)$ were snap frozen in liquid nitrogen and stored at $-80^{\circ} \mathrm{C}$.

\section{Immunohistochemistry}

As described previously [17], cross-sections of airways $2 \mu \mathrm{m}$ in thickness were deparaffinised in xylene and rehydrated in ethanol and PBS. Endogenous peroxidase activity was inactivated using $1 \%$ hydrogen peroxide in methanol (Roth, Karlsruhe, Germany; pH 7.2) for $30 \mathrm{~min}$. Antigen retrieval was performed by microwave treatment in 3\% citrate buffer (Roth; pH 6.0). After washing in PBS, the sections were incubated in PBS containing $1 \%$ bovine serum albumin (Serva, Heidelberg, Germany) for $30 \mathrm{~min}$ followed by incubation with a polyclonal rabbit antibody (courtesy of J. Klug, Justus Liebig University, Marburg, Germany) directed against Clara cell-specific 10-kDa protein (CC10) diluted 1:3,000 in the same solution for $1 \mathrm{~h}$ at $37^{\circ} \mathrm{C}$. Sections were then incubated with an anti-rabbit secondary antibody diluted 1:10 for $30 \mathrm{~min}$ at room temperature. This was visualised using 3,3'-diaminobenzidine as chromogen according to the $\mathrm{ABC}$ method (Vectastain Elite ABC Kit; Vector Laboratories, Burlingame, CA, USA) and following the manufacturer's instructions. In order to identify ciliated cells and cell proliferation, immunostaining was performed using mouse monoclonal antibodies directed against $\beta$-Tubulin-IV (Bio Genex, San Ramon, CA, USA; 1:150 dilution) and against proliferating cell nuclear antigen (PCNA; Dako Cytomation, Hamburg, Germany; 1:600 dilution), respectively. Antibodies were detected using a mouse-on-mouse immunodetection kit (Vector MOM kit; Vector Laboratories). All sections were counterstained with haematoxylin.

\section{Quantitative-morphological analysis}

The number of Clara cells was determined by design-based stereology using a physical dissector [30]. Clara cell numbers were normalised to the area of the airway epithelial basal lamina. In addition, the arithmetic mean thickness of Clara cells was estimated by point and intersection counting. Four to six paraffin-embedded airways were studied per mouse. From each airway, two serial cross-sections were cut using a motorised microtome with a block-cooling device (H 355 S; Microm, Walldorf, Germany), which was calibrated for block advance. Sections $2 \mu \mathrm{m}$ in thickness were stained for CC10 and analysed by means of a computer-assisted Olympus BX 51 light microscope, which was equipped with a CAST-Grid System (Olympus, Ballerup, Denmark).

The arithmetic mean thickness of Clara cells ( $\bar{\tau} \mathrm{CC})$ was calculated using the following equation:

$$
\bar{\tau} \mathrm{CC}=2 \mathrm{PCC} \cdot \mathrm{l}_{\mathrm{C}} / \pi \mathrm{IBL},
$$

where PCC is the sum of points that hit the Clara cells, lc is the length per point on a cycloid grid and IBL is the sum of intersections of cycloid test lines with the epithelial basal lamina.

The number of Clara cells (ncc) was calculated, using Equation 2 , from their numerical density (ncC per volume of epithelium (VEPI; nVCC,EPI)), which was determined using Equation 3 and normalised to the surface area of the basal lamina (SBL) in the same reference volume, estimated using Equation 4:

$$
\begin{gathered}
\mathrm{nSCC}, \mathrm{BL}=\mathrm{n} V C \mathrm{C}, \mathrm{EPI} / \mathrm{S} V \mathrm{BL}, \mathrm{EPI} \\
\mathrm{n} V \mathrm{CC}, \mathrm{EPI}=0.5 \mathrm{ct} / \mathrm{PEPI} \cdot \mathrm{Afr} \cdot \mathrm{H} \\
\mathrm{S} V \mathrm{BL}, \mathrm{EPI}=\pi \mathrm{IBL} / 2 l_{\mathrm{c}} \cdot \mathrm{PEPI}
\end{gathered}
$$

where $\mathrm{nSCC}, \mathrm{BL}$ is the nCC per SBL, SVBL,EPI the SBL per VEPI, ct the number of nuclear profiles of CC10 immunoreactive cells in the look-up section of the dissector, which are not seen in the reference section, PEPI the sum of points hitting airway epithelium, Afr the area of the unbiased counting frame and $\mathrm{H}$ the height of the dissector (i.e. the calibrated mean block advance of $2 \mu \mathrm{m})$. Since counting was performed in both directions (double dissector), ct was multiplied by 0.5 in Equation 2.

\section{RNA isolation and real-time RT-PCR}

Total RNA was isolated from microdissected airways using the SV Total RNA Isolation System (Promega, Mannheim, Germany), and cDNA was synthesised using the Omniscript Reverse Transcription Kit (Qiagen, Hilden, Germany). Real-time RTPCR was performed using the QuantiTect ${ }_{\mathbb{R}}$ SYBR $_{\mathbb{B}}$ Green Master Mix (Abgene, Hamburg, Germany) and BioRad ICycler (BioRad Laboratories, Munich, Germany). QuantiTect ${ }_{\circledR}$ SYBR $_{\circledR}$ Green Master Mix $(10 \mu \mathrm{L}), 1 \mu \mathrm{L}$ of each primer at a concentration of $50 \mathrm{pmol} \cdot \mu \mathrm{L}^{-1}$ and $20 \mu \mathrm{L}$ water were added to $3 \mu \mathrm{L} \mathrm{cDNA}$, standard or water (negative control). Primer sequences were generated from the respective mRNA sequences obtained from the European Molecular Biology Laboratory gene bank (Heidelberg, Germany; table E1 of online supplementary material). Primers were synthesised by MWG Biotech (Ebersberg, Germany). Change in cycle threshold analysis was used to determine expression in comparison to reduced glyceraldehye-3phosphate dehydrogenase (GAPDH). In additional, because NA caused Clara cell exfoliation and the CYP2F2 isozyme is predominantly expressed in Clara cells, CYP2F2 mRNA expression was determined relative to CC10 mRNA expression.

\section{Effects of 4 N23-KGF on Clara cells cultured in vitro}

Mouse Clara cells were isolated from C57BL/6 mice using the protocol described by ELIZUR et al. [31], from which a Clara cell 
purity of $70 \%$ was obtained. Briefly, the lung was perfused free of blood with PBS via the right ventricle, $1 \mathrm{~mL} \mathrm{1 \%} \mathrm{low} \mathrm{melting-}$ point agarose in PBS was instilled through the trachea followed by $0.5 \mathrm{~mL} 0.25 \%$ bovine pancreatic trypsin (SigmaAldrich). Following incubation on ice, the lungs were excised and incubated for $10 \mathrm{~min}$ at $37^{\circ} \mathrm{C}$. The tissues were diced in medium (Dulbecco's modified Eagle medium containing $250 \mu \mathrm{g} \cdot \mathrm{mL}^{-1}$ DNase and $2 \times$ antibiotic/antimycotic) filtered sequentially through $100-$ and $40-\mu \mathrm{m}$ filters. The final pellet was resuspended in $10 \mathrm{~mL}$ medium. For experiments, cells were placed into 35-mm cell culture plates. Cells received fresh medium supplemented with either $\Delta \mathrm{N} 23-\mathrm{KGF}\left(50 \mathrm{ng} \cdot \mathrm{mL}^{-1}\right)$ or an equivalent volume of PBS as control. After 1 and $4 \mathrm{~h}$ of in vitro culture at $37^{\circ} \mathrm{C}$, the RNA Lysis buffer (SV Total RNA Isolation System) covering the cells was collected and the cells harvested for RNA isolation and subsequent real-time RT-PCR analysis as described above.

\section{Noninvasive measurement of lung function}

Immediately prior to sacrifice, mid-expiratory airflow (EF50; measured in $\mathrm{mL} \cdot \mathrm{s}^{-1}$ ), a parameter suitable for monitoring broncho-obstruction [27], was measured using head-out body plethysmography as described previously [32]. Briefly, the system consisted of a glass body to which four head-out body plethysmograph chambers were attached (Forschungswerkstätten, Hanover Medical School, Hanover, Germany). A calibrated pneumo-tachograph (PTM 378/1.2; Hugo Sachs Electronics, March-Hugstetten, Germany) and a differential pressure transducer (8T-2; Gaeltec, Dunvegan, UK) coupled to an amplifier (Gould Universal Amplifier; Gould, Dietzenbach, Germany) were attached to the top port of each plethysmograph chamber. The amplified analogue signal from the pressure transducer was digitised via an analogue-to-digital converter (DAS-16; Keithley, Germering, Germany) at a sampling frequency of 2,000 s-1. For airflow measurements, one mouse was placed into each chamber with the head protruding through a flexible neck collar so that the chamber was sealed in an airtight fashion against the main glass body. Airflow was measured during a 15 -min period after the animals had resumed normal breathing. EF50 measured following treatment with $\triangle \mathrm{N} 23-\mathrm{KGF}$ and/or NA were expressed as percentage changes from the mean baseline value of the respective control group.

\section{Statistical analysis}

Data are presented as mean \pm SD unless otherwise stated. Oneway ANOVA was used to determine the significance of differences observed between groups if normality and equal variance corresponded to $\mathrm{p}>0.1$. Otherwise, Kruskal-Wallis ANOVA on ranks was used. A p-value of $<0.05$ was considered significant.

\section{RESULTS}

\section{Pre-treatment with 4 N23-KGF protects Clara cells against naphthalene-induced necrosis}

Failure of cell membrane integrity was assessed using EH-1, a sensitive indicator of irreversible cell injury [29]. EH-1-positive cells, which were identified as Clara cells based on morphological characteristics, were abundant in the distal airways of mice $12 \mathrm{~h}$ after injection of $200 \mathrm{mg} \cdot \mathrm{kg}$ body weight ${ }^{-1} \mathrm{NA}$ (fig. 1b), whereas EH-1-positive cells were completely absent from control mice (fig. 1a) or mice treated with $\Delta$ N23-KGF (fig. 1c). Pre-treatment of lungs with $\Delta$ N23-KGF prior to injection of NA markedly reduced the appearance of EH-1positive cells in distal airway epithelium (fig. 1d).

\section{\N23-KGF induces PCNA activation and airway epithelial proliferation}

PCNA is a proliferation marker as its gene is expressed from early in the $G_{1}$ phase to the $S$ phase of the cell cycle, with the protein confined to the nucleus. Epithelial cells showing nuclear staining for PCNA were rarely observed in untreated airways (fig. 2a). Immunoreactivity for PCNA was regularly observed in airway epithelial cells of mice $12 \mathrm{~h}$ after injection of NA (fig. 2b). However, PCNA-positive cells were abundant in the distal airways of lungs pre-treated with $\triangle \mathrm{N} 23-\mathrm{KGF}$ (fig. 2c and d).

Quantitative real-time RT-PCR revealed that, in mice pretreated with $\triangle \mathrm{N} 23-\mathrm{KGF} 33 \mathrm{~h}$ prior to injection of NA, PCNA mRNA expression was significantly increased compared with mice injected with NA that had been pre-treated with PBS (fig. 2e).

\section{Pre-treatment with $\triangle$ N23-KGF inhibits Clara cell loss}

Clara cells were identified immunohistochemically via CC10, which is also known as CC16, uteroglobin or secretoglobin [33]. Clara cell numbers were analysed using design-based stereology with a physical dissector approach. Quantitative morphological analysis revealed that, $12 \mathrm{~h}$ after injection of $\mathrm{NA}$, the number of CC10-positive Clara cells per square millimeter of basement membrane (BM; 5,047 \pm 829$)$ was reduced to $50 \%$ of the Clara cell number characteristic of the distal airways of control mice $\left(10,157 \pm 229\right.$ cells $\left.\cdot \mathrm{mm} \mathrm{BM}^{-2}\right)$. Pre-treatment of lungs with $\Delta$ N23-KGF caused a slight increase in Clara cell number after $33 \mathrm{~h}\left(12,142 \pm 399\right.$ cells $\left.\cdot \mathrm{mm} \mathrm{BM}^{-2}\right)$ and significantly restricted the loss of Clara cells $12 \mathrm{~h}$ after NA treatment $\left(9,404 \pm 528\right.$ cells $\left.\cdot \mathrm{mm} \mathrm{BM}^{-2}\right)$ to only $23 \%$ of that of lungs treated with $\Delta$ N23-KGF alone (fig. 3).

Consistent with the physical dissector counts of Clara cell numbers, real-time RT-PCR showed significantly reduced CC10 relative to GAPDH mRNA expression in the distal airways of NA-treated mice (4.4\% of PBS control), whereas the CC10 mRNA level in airways of mice pre-treated with $\Delta$ N23KGF prior to injection of NA was approximately four-fold higher (fig. 4). KGF has previously been shown to decrease CC10 mRNA expression levels in rat Clara cells [34]. Consequently, pre-treatment with $\triangle \mathrm{N} 23-\mathrm{KGF}$ alone resulted in a reduction in CC10 mRNA expression compared with PBStreated control mice despite the increase in proliferation and Clara cell numbers.

\section{AN23-KGF downregulates cytochrome $P_{450} 2$ F2 mRNA expression}

CYP2F2 is important in the metabolism of NA since it converts NA into a cytotoxic epoxide intermediate. Administration of $\Delta \mathrm{N} 23-\mathrm{KGF}$ with or without subsequent injection of NA resulted in significant downregulation of CYP2F2 mRNA expression (fig. 5). This was corroborated by real-time RTPCR analyses of Clara cell-enriched lung epithelial cells isolated from mouse lungs. After $4 \mathrm{~h}$ of incubation of isolated Clara cells with $\triangle \mathrm{N} 23-\mathrm{KGF}$ in vitro, the level of CYP2F2 mRNA 

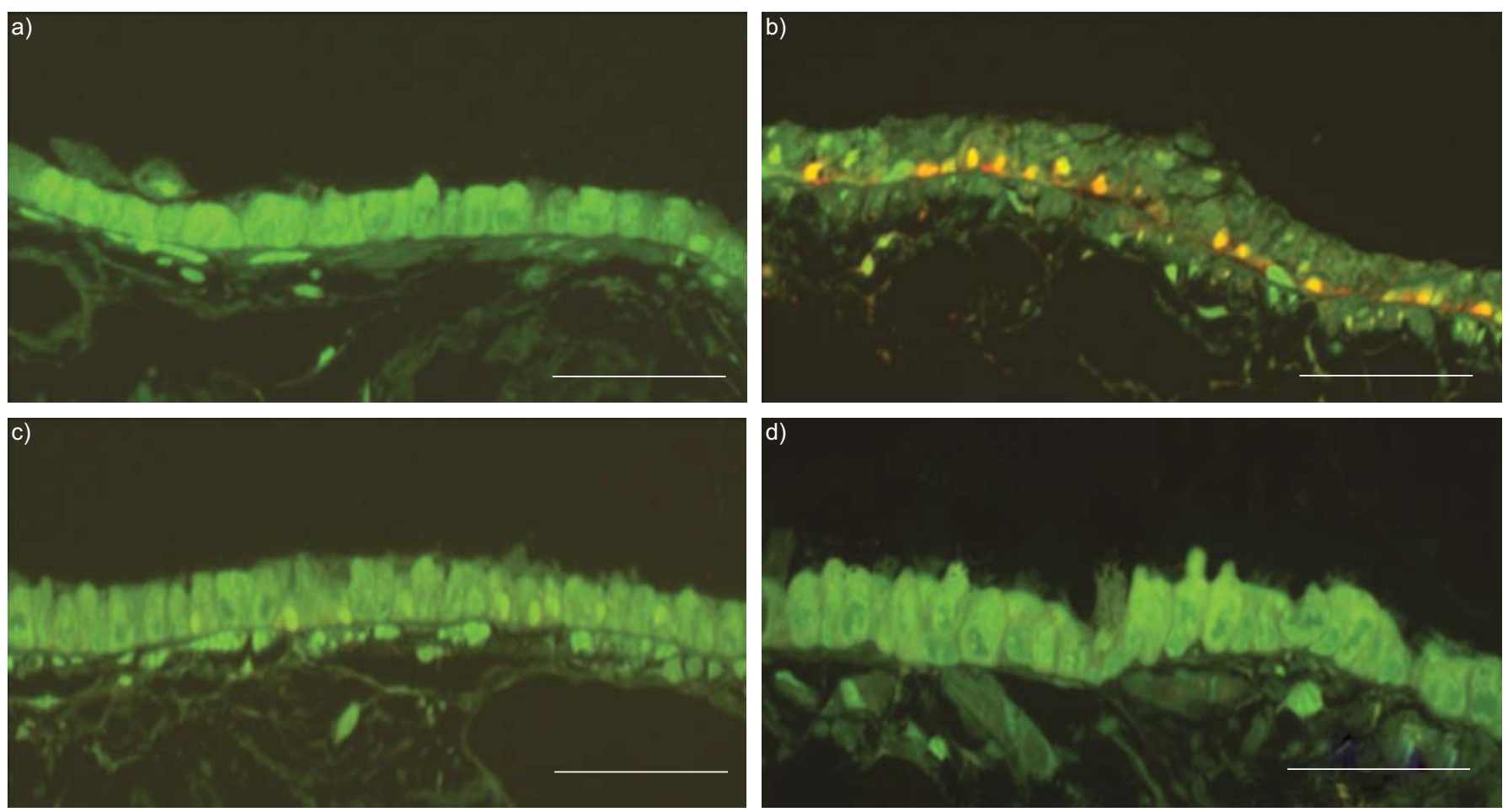

FIGURE 1. Ethidium homodimer-1 staining (red-orange) of the distal airways of mice. Mice were treated with a, c) corn oil and b, d) naphthalene (200 mg $k \mathrm{~kg}$ body

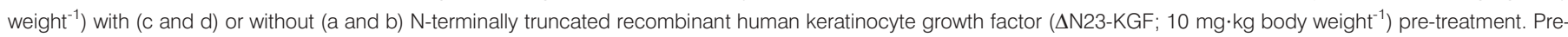
treatment with $\triangle N$ 23-KGF protected Clara cells against naphthalene-induced necrosis. The images are representative of four distal airways per mouse ( $n=3$ mice per group) Scale bar $=50 \mu \mathrm{m}$.

expression was significantly decreased (fig. 6). Since NA resulted in a significant loss of Clara cells $12 \mathrm{~h}$ after injection, normalisation of CYP2F2 to GAPDH mRNA expression is problematic in that a reduction in CYP2F2 mRNA expression might simply reflect the loss of Clara cells. Therefore, CYP2F2 mRNA expression was instead normalised to CC10 mRNA expression. Since treatment with $\Delta \mathrm{N} 23-\mathrm{KGF}$ alone reduces CC10 expression, this procedure is likely to result in underestimation rather than overestimation of the effect of $\triangle \mathrm{N} 23-\mathrm{KGF}$ on $\mathrm{CYP} 2 \mathrm{~F} 2$.

\section{Pre-treatment with AN23-KGF prevents naphthalene- induced impairment of lung function}

In order to assess the functional relevance of NA-induced acute airway injury and of the effect of $\triangle \mathrm{N} 23-\mathrm{KGF}$, airflow was investigated by means of head-out body plethys-mography. At $33 \mathrm{~h}$ following administration, $\triangle \mathrm{N} 23-\mathrm{KGF}$ or PBS alone had no significant effect on EF50 compared with EF50 recorded immediately prior to pre-treatment $(0 \mathrm{~h}), 0.74 \pm 0.18 \mathrm{~mL} \cdot \mathrm{s}^{-1}$ in PBS treated mice and $0.78 \pm 0.43 \mathrm{~mL} \cdot \mathrm{s}^{-1}$ in mice treated with $\triangle \mathrm{N} 23-\mathrm{KGF}$. However, $12 \mathrm{~h}$ after injection of NA, there was a significant reduction in EF50 recorded from mice pre-treated with PBS, whereas EF50 did not change in mice pre-treated with $\triangle \mathrm{N} 23-\mathrm{KGF}$ (fig. 7).

\section{Therapeutic effect of 4 N23-KGF after naphthalene-induced airway epithelial injury depends on the presence of Clara cells}

In order to test the hypothesis that the protective effect of $\triangle \mathrm{N} 23-\mathrm{KGF}$ is primarily related to Clara cells, treatment with $\Delta \mathrm{N} 23-\mathrm{KGF}$ was performed $2 \mathrm{~h}$ after injection of $\mathrm{NA}$, when
Clara cells are already injured but still present, or $24 \mathrm{~h}$ after injection, a time-point at which Clara cells are almost completely lost from the distal airway epithelium (fig. E1 of online supplementary material). In mice treated with $\Delta \mathrm{N} 23$ KGF $2 \mathrm{~h}$ after injection of NA, Clara cell numbers were significantly higher than in mice injected with NA and only slightly and insignificantly lower than in control mice injected with corn oil (fig. 8). In contrast, in mice receiving $\Delta$ N23-KGF $24 \mathrm{~h}$ after injection of NA, Clara cell numbers were similar to those found in mice injected with NA and significantly lower than in control mice injected with corn oil.

\section{DISCUSSION}

KGF is a potent mitogen for epithelial cells and has been demonstrated to protect the lung against acute injuries of the pulmonary parenchyma in various animal models [14] However, its potential for protecting against airway epithelial injury has not been well characterised. Therefore, the aim of the present study was to investigate whether or not pretreatment with $\triangle \mathrm{N} 23-\mathrm{KGF}$ or palifermin, which results in enhanced KGF protein stability [25], protects the airway epithelium against NA-induced acute airway injury in vivo. Three experimental approaches were used in addressing this question. These approaches defined different aspects of the cell biology of the early injury process, the effect of treatment on pulmonary function and the effect of KGF treatment on the biology of the airway epithelium. It was found that $\triangle \mathrm{N} 23-\mathrm{KGF}$ prevented the NA-induced loss of cell membrane integrity, increased airway epithelial cell proliferation and largely reduced the loss of Clara cells, as well as the impairment of 

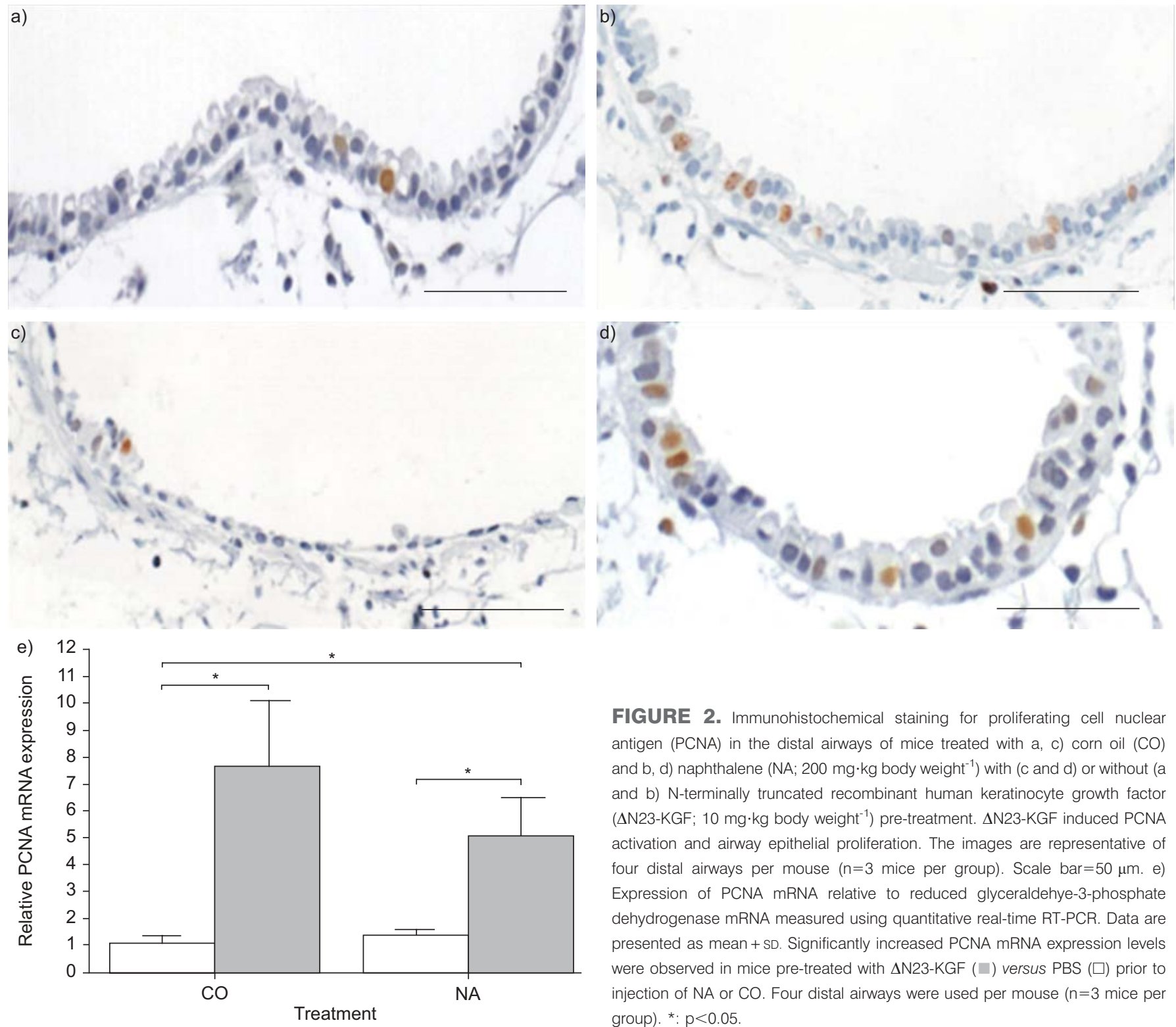

FIGURE 2. Immunohistochemical staining for proliferating cell nuclear antigen (PCNA) in the distal airways of mice treated with a, c) corn oil (CO) and b, d) naphthalene (NA; $200 \mathrm{mg} \cdot \mathrm{kg}$ body weight ${ }^{-1}$ ) with (c and d) or without (a and b) N-terminally truncated recombinant human keratinocyte growth factor $\left(\Delta \mathrm{N} 23-\mathrm{KGF} ; 10 \mathrm{mg} \cdot \mathrm{kg}\right.$ body weight ${ }^{-1}$ ) pre-treatment. $\Delta \mathrm{N} 23-\mathrm{KGF}$ induced PCNA activation and airway epithelial proliferation. The images are representative of four distal airways per mouse ( $n=3$ mice per group). Scale $b a r=50 \mu m$. e) Expression of PCNA mRNA relative to reduced glyceraldehye-3-phosphate dehydrogenase mRNA measured using quantitative real-time RT-PCR. Data are presented as mean + SD. Significantly increased PCNA mRNA expression levels were observed in mice pre-treated with $\triangle$ N23-KGF ( $\square$ ) versus PBS $(\square)$ prior to injection of NA or $\mathrm{CO}$. Four distal airways were used per mouse $(\mathrm{n}=3$ mice per group). *: $p<0.05$.

lung function due to NA-induced acute airway injury. The decrease in CYP2F2 mRNA expression in microdissected distal airways, as well as in isolated Clara cells, indicates that $\Delta \mathrm{N} 23$ KGF exerted its protective effects, at least in part, through downregulation of this NA-metabolising xenobiotic enzyme. The failure of $\Delta \mathrm{N} 23-\mathrm{KGF}$ to ameliorate NA-induced injury when applied $24 \mathrm{~h}$ after injection of NA, i.e. at a time-point at which Clara cells are almost completely lost from the distal airway epithelium, demonstrates that the protective effect of $\Delta \mathrm{N} 23-\mathrm{KGF}$ is primarily related to Clara cells.

The NA model of airway epithelial cell injury has been well established in the mouse [13,35]. The high susceptibility to NA cytotoxicity has been revealed to be associated with the expression of CYP2F2 in Clara cells of the distal airway epithelium of the mouse [12]. Although the cytotoxic effect of NA had been extensively investigated in Swiss Webster $[9,36]$ and FVB mice [37-40], little was known about NA-induced

injury to the distal airway epithelium of C57BL/6 mice [41, 42], this being particularly true for the early time course. In order to define the optimal time-point for the analysis of potential protective effects of $\Delta \mathrm{N} 23-\mathrm{KGF}$ against NA-induced Clara cell injury, the kinetics of NA-induced effects on the distal airway epithelium were investigated first. The sequence of events in C57BL $/ 6$ mice following injection of $200 \mathrm{mg} \cdot \mathrm{kg}$ body weight ${ }^{-1}$ NA was similar to that seen in Swiss Webster mice. At $3 \mathrm{~h}$ after injection of NA, Clara cells exhibited slight swelling and onset of vacuolisation, with exfoliation being almost complete by $24 \mathrm{~h}$, which is in line with previous findings in C57BL/6 mice [41, 42]. After $12 \mathrm{~h}$, most of the Clara cells were swollen and contained vacuoles, but only half of them were lost by exfoliation. Therefore, this time-point was chosen for revealing the potential protective effects of $\Delta \mathrm{N} 23-\mathrm{KGF}$ on NA-induced Clara cell injury.

Previous studies have adapted EH-1 for use on microdissected airways and demonstrated it to be a reliable probe for cells 


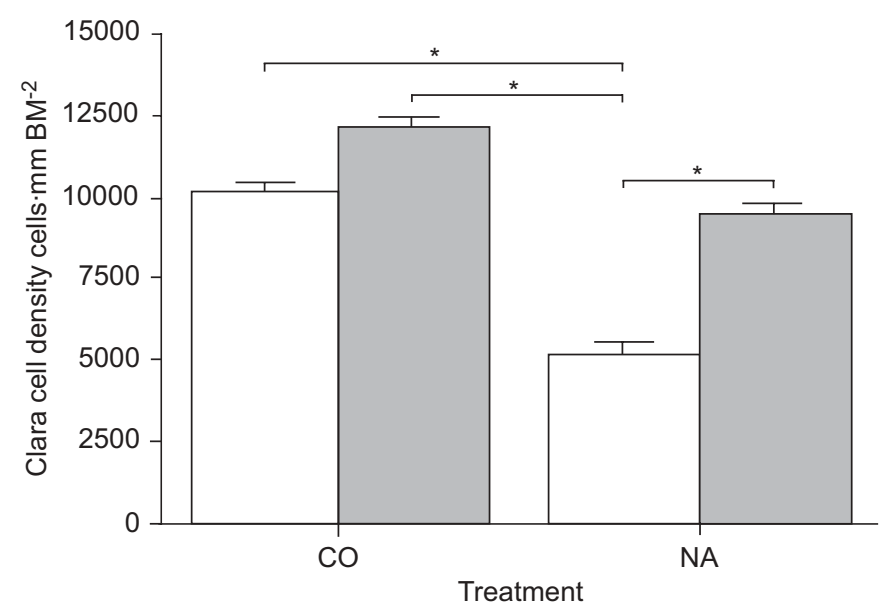

FIGURE 3. Design-based stereological estimation of the number of Clara cellspecific 10-kDa protein-positive Clara cells in distal airways obtained from mice pretreated with PBS $(\square)$ or N-terminally truncated recombinant human keratinocyte growth factor ( $\triangle \mathrm{N} 23-\mathrm{KGF}$; $)$ ) prior to injection of corn oil (CO) or naphthalene (NA). Data are presented as mean $+S D$. Pre-treatment with $\triangle$ N23-KGF inhibited Clara cell loss. Four distal airways were used per mouse ( $n=3$ mice per group). BM: basement membrane. *: $p<0.05$.

undergoing necrosis [43]. Intraperitoneal injection of NA resulted in a marked increase in EH-1-permeable Clara cells by $6 \mathrm{~h}$ after injection in Swiss Webster mice [29], and $12 \mathrm{~h}$ after injection in C57BL/6 mice in the present study, indicating that NA-induced exfoliation of Clara cells was due to necrosis. Pretreatment of C57BL/6 mice with $\triangle \mathrm{N} 23-\mathrm{KGF}$ largely abolished the incorporation of EH-1 into Clara cell nuclei, which suggests that $\Delta \mathrm{N} 23-\mathrm{KGF}$ protects Clara cells of the distal airways against NA-induced necrotic cell death. As a consequence, in mice pre-treated with $\Delta \mathrm{N} 23-\mathrm{KGF}$, only $23 \%$ of the Clara cells were lost $12 \mathrm{~h}$ after injection of NA, whereas $50 \%$ were lost in mice pre-treated with control vehicle, as demonstrated using design-based quantitative morphology [30]. Similarly, after injection of NA in mice pre-treated with PBS, CC10 mRNA expression was reduced to $<5 \%$ of that of control mice, whereas, in mice pre-treated with $\Delta \mathrm{N} 23-\mathrm{KGF}$, expression of CC10 mRNA was $38 \%$ of that recorded in controls treated with $\triangle \mathrm{N} 23-\mathrm{KGF}$ alone. The reduction in CC10 mRNA expression in $\Delta$ N23-KGF-treated animals is probably a consequence of the decrease in the number of CC10 transcripts per cell, demonstrated by in situ hybridisation studies [34], rather than a result of Clara cell exfoliation. The marked loss of Clara cells following injection of NA is likely to affect the barrier function of the airway epithelium and KGF can be suspected to maintain airway epithelial integrity, which is essential to, for example, lung fluid balance, host defence, and clearance or metabolism of inhaled agents [10]. This is in line with in vitro studies that have demonstrated KGF to protect monolayers of bronchial epithelial cells against loss of barrier function induced by hydrogen peroxide [19] or irradiation [18].

Head-out body plethysmography was used to assess the effects of airborne chemicals on respiratory function [44]. The present study demonstrated for the first time that acute airway epithelial damage caused by NA was associated with significant airway dysfunction, indicating that the highly

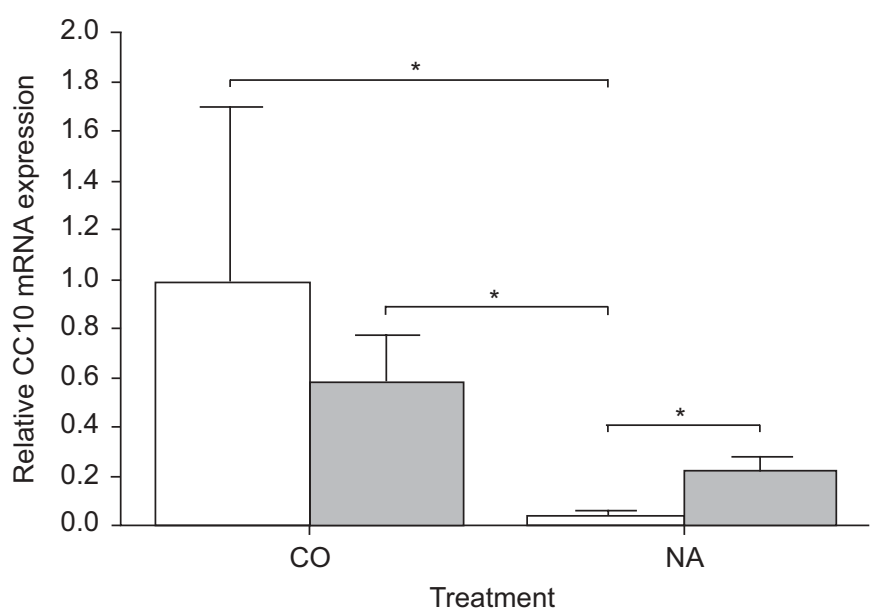

FIGURE 4. Quantitative real-time RT-PCR analysis using Clara cell-specific 10kDa protein (CC10)-specific primer pairs. CC10 mRNA expression was determined relative to that of reduced glyceraldehye-3-phosphate dehydrogenase. Total RNA was isolated from mice pre-treated with PBS $(\square)$ or N-terminally truncated recombinant human keratinocyte growth factor $(\square)$ prior to injection of corn oil $(\mathrm{CO})$ or naphthalene (NA). Data are presented as mean $+\mathrm{SD}$. Three distal airways were used per mouse ( $n=3$ mice per group). ${ }^{*}: p<0.05$.

specific injury to Clara cells resulted in significant functional impairment at the organ level. Whether this is the result of changes in airway permeability or inflammation, a direct effect of NA on airway smooth muscle or an indirect effect due to the alterations in the airway epithelium remains to be elucidated. Pre-treatment of mice with $\Delta \mathrm{N} 23-\mathrm{KGF} 33 \mathrm{~h}$ prior to NAinduced airway injury almost completely prevented the impairment of EF50. In previous studies, comparing noninvasive measurement of EF50 with invasive measurement of pulmonary conductance $(G \mathrm{~L})$ and dynamic compliance, very good agreements between EF50, GL and dynamic compliance were observed $[45,46]$. During airway constriction, the main changes in the tidal flow signal, recorded by head-out body plethysmography, occur during the mid-expiratory phase. Therefore, the EF50 was defined as the tidal flow at the midpoint $(50 \%)$ of expiratory tidal volume [46]. Consequently, EF50 is closely linked to tidal volume and expiration time. However, EF50 was clearly demonstrated to be independent of respiratory frequency [45]. Only a slight and insignificant decrease in EF50 was observed $33 \mathrm{~h}$ after instillation of $\Delta \mathrm{N} 23-\mathrm{KGF}$, whereas modest-but-significant changes in lung resistance and forced expiratory airflow were seen by invasive lung function analysis 3 days after treatment with $\Delta \mathrm{N} 23-\mathrm{KGF}$ in rats [47]. These differences may relate to the fact that noninvasive assessment of lung function is less sensitive than invasive measurement of respiratory function parameters in anaesthetised and intubated animals [27], although the possibility that there may be quantitative differences between mice and rats in their response to $\Delta$ N23-KGF cannot be ruled out.

Clara cells are the preferred progenitor cell for regeneration of the distal airway epithelium following injury [9, 37, 38]. Transdifferentiation of ciliated cells has been suggested to significantly contribute to epithelial repair following NAinduced injury [40]. Recently, however, RAwLINS et al. [42] suggested that a small population of variant Clara cells, which 


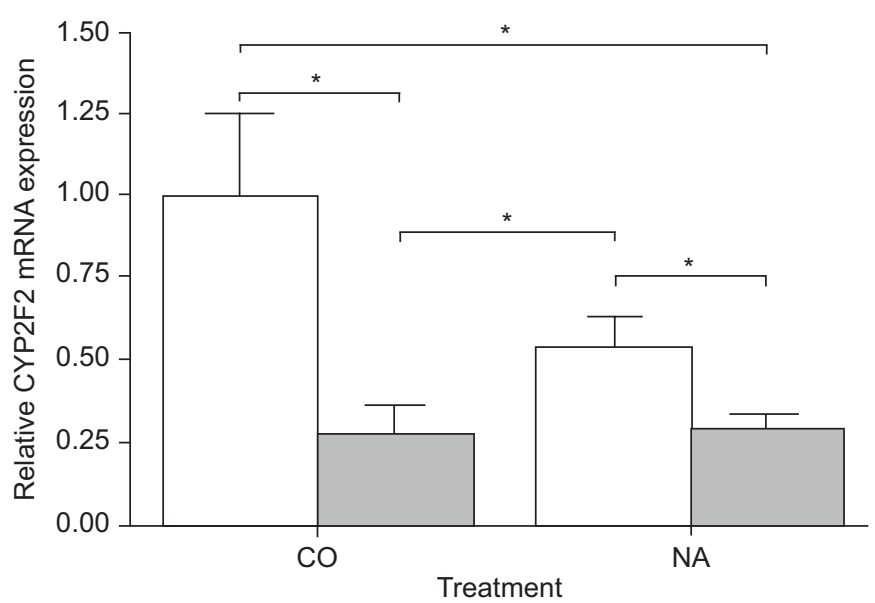

FIGURE 5. Quantitative real-time RT-PCR analysis using primer pairs specific for cytochrome $\mathrm{P}_{450}$ isozyme 2F2 (CYP2F2). CYP2F2 mRNA expression was determined relative to that of Clara cell-specific 10-kDa protein. Total RNA was isolated from mice pre-treated with PBS $(\square)$ or N-terminally truncated recombinant human keratinocyte growth factor ( $\triangle \mathrm{N} 23-\mathrm{KGF}$; ${ }^{-1}$ ) prior to injection of corn oil (CO) or naphthalene (NA). Data are presented as mean + SD. $\triangle$ N23-KGF downregulated CYP2F2 mRNA expression in vivo. Three distal airways were used per mouse $(n=3$ mice per group). ${ }^{*}: p<0.05$.

survive after NA injury, are most probably the progenitors of Clara cells following NA injury. Their data suggest that ciliated cells do not transdifferentiate into Clara cells. Human recombinant KGF was shown to stimulate DNA synthesis and proliferation of human bronchial epithelial cells in vitro and of rat and mouse airway epithelium in vivo. It has previously been demonstrated that the KGF-induced stimulation of distal airway epithelial proliferation was restricted to Clara cells, and peaked between days 1 and 2 following intratracheal instillation of KGF into rat lungs in vivo [17]. In the present study, a similar strong induction of mouse Clara cell proliferation in response to exogenous $\Delta$ N23-KGF was observed, as evidenced by both PCNA immunohistochemistry and quantitative real-time RT-PCR for detection of PCNA mRNA expression. Consequently, Clara cell numbers were increased by $\sim 20 \%$ in mice $33 \mathrm{~h}$ after treatment with $\Delta \mathrm{N} 23$ KGF compared with control treated mice. At $12 \mathrm{~h}$ after NA treatment, no significant proliferation of airway epithelium was observed in C57BL/6 mice treated with NA alone. However, proliferation of distal airway epithelium was demonstrated at later time-points, and was shown to peak at day 2 after injection of NA into Swiss Webster mice [9, 37]. Notably, the induction of this endogenous repair process was recently suggested to be related to the upregulation of airway epithelial expression of KGF receptor at day 1 after NAinduced injury [48].

In rats, Northern blot analysis of whole lung homogenate revealed that administration of KGF in vivo led to a significant decrease in CC10 mRNA expression on days 2 and 3 compared with vehicle-treated control lungs and then gradually recovered to normal values [34]. In the present study, treatment with $\Delta$ N23-KGF resulted in a slight, albeit insignificant, decrease in CC10 mRNA expression in the distal airways of C57BL/6 mice, which might relate to the earlier time-point examined in

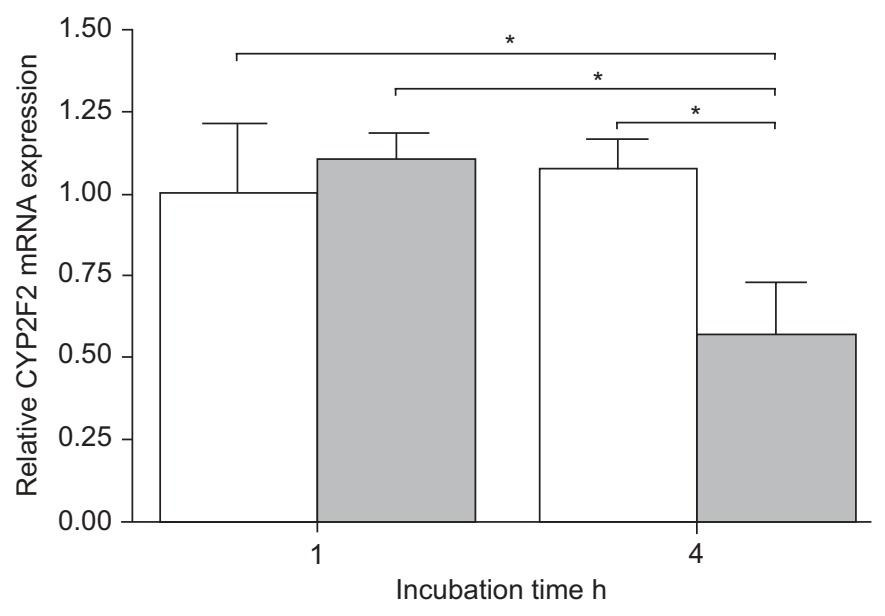

FIGURE 6. Quantitative real-time RT-PCR analysis using primer pairs specific for cytochrome $\mathrm{P}_{450}$ isozyme 2F2 (CYP2F2). CYP2F2 mRNA expression was determined relative to that of Clara cell-specific $10-k D a$ protein. Total RNA was obtained from Clara cell-enriched lung epithelial cells isolated from the lungs of C57BL/6 mice. Isolated cells were harvested after 1 and $4 \mathrm{~h}$ of incubation with PBS $(\square)$ or cell culture medium that contained $50 \mathrm{ng} \cdot \mathrm{mL}^{-1} \mathrm{~N}$-terminally truncated recombinant human keratinocyte growth factor ( $\triangle \mathrm{N} 23-\mathrm{KGF} ; \mathbf{\square})$. Data are presented as mean $+\mathrm{SD}$. $\triangle \mathrm{N} 23-\mathrm{KGF}$ downregulated CYP2F2 mRNA expression in vitro. $\mathrm{n}=3$ mice per group. *: $p<0.05$.

the present study. In rats, the decrease in CC10 mRNA levels appeared to be due to decreased expression per cell, as assessed by in situ hybridisation [34]. Correspondingly, CC10, assessed by quantitative immunohistochemistry, exhibited decreased immunoreactivity per cell in distal rat airway epithelium [17]. In response to intratracheal administration of exogenous KGF in vivo, a quantitative shift from Clara cells exhibiting normal strong staining for CC10 to them exhibiting weak immunoreactivity for CC10 was observed. The findings of these studies suggested that the reduction in CC10 mRNA and protein

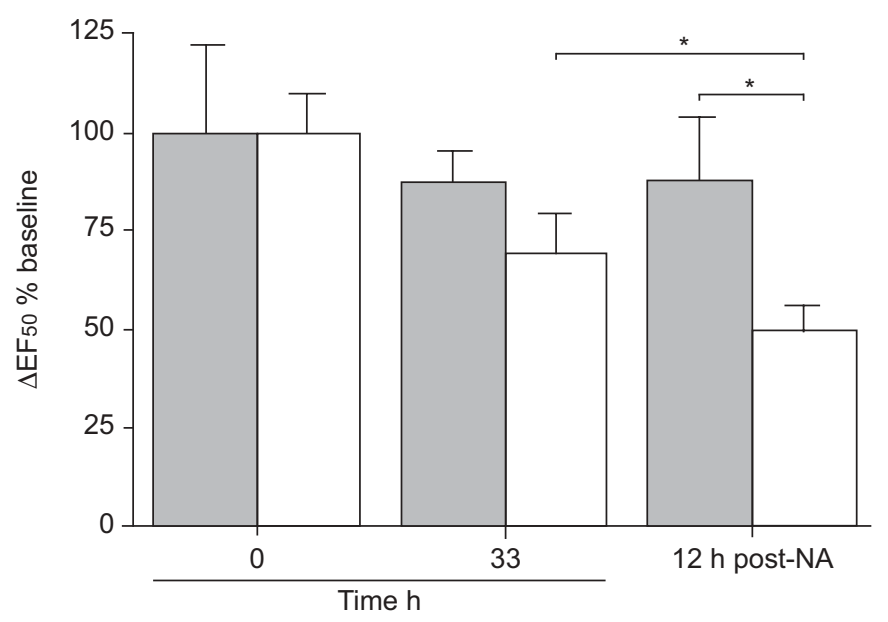

FIGURE 7. Noninvasive head-out body plethysmography of mice prior to $(0 \mathrm{~h}$; baseline) and $33 \mathrm{~h}$ after pre-treatment with $\mathrm{N}$-terminally truncated recombinant human keratinocyte growth factor ( $\triangle \mathrm{N} 23-\mathrm{KGF} ; \square)$ or PBS $(\square)$, and $12 \mathrm{~h}$ after the injection of naphthalene (NA) following pre-treatment. Data are presented as mean + SD. Pre-treatment with $\Delta$ N23-KGF prevented NA-induced impairment of lung function. $n=6$ mice per group. $\Delta E F 50$ : change in mid-expiratory airflow. *: $p<0.05$. 


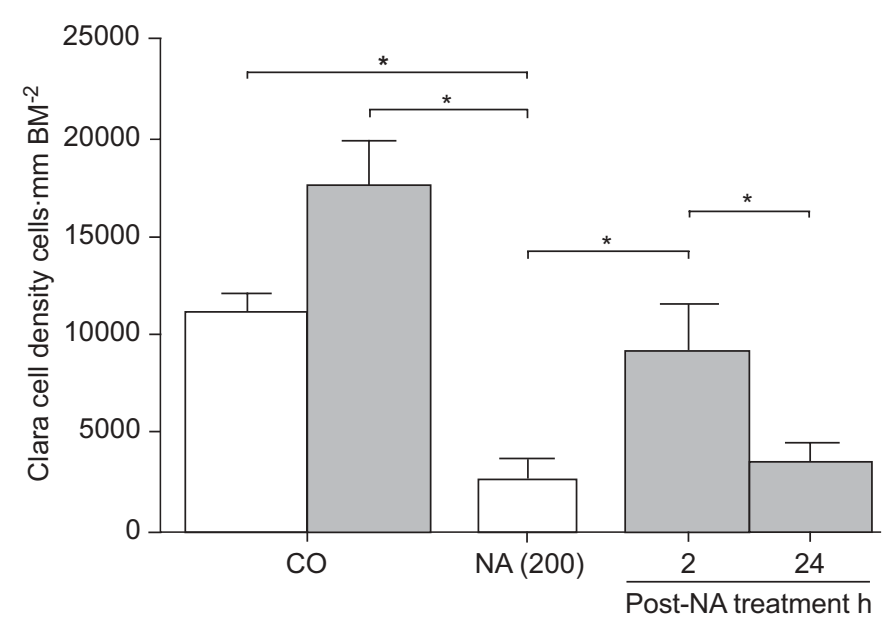

FIGURE 8. Design-based stereological estimation of the number of Clara cellspecific $10-k D a$ protein-positive Clara cells in distal airways obtained from mice treated with PBS $(\square)$ or N-terminally truncated recombinant human keratinocyte growth factor ( $\triangle \mathrm{N} 23-\mathrm{KGF}$; $\square$ ) after injection of $200 \mathrm{mg} \cdot \mathrm{kg}$ body weight ${ }^{-1}$ naphthalene (NA) or corn oil (CO). Airways were obtained by microdissection on day 5 after injection of $\mathrm{CO}$ or NA. The therapeutic effect of $\triangle$ N23-KGF following NAinduced airway epithelial injury depended upon the presence of Clara cells. Data are presented as mean $+S D$. Four distal airways were used per mouse $(n=3$ mice per group). BM: basement membrane. ${ }^{*}: p<0.05$

expression was not the result of a decrease in the number of CC10-expressing Clara cells but reflected decreased expression per cell. This is supported by the present findings that Clara cell numbers were increased by $20 \%$, whereas CC10 mRNA expression was concomitantly decreased down to $\sim 60 \%$ in mice treated with $\Delta$ N23-KGF compared with vehicle controls.

The species-specific and region-selective cytotoxicity of NA has been directly linked to its metabolism to NA $1 R, 2 S$-oxide, which is catalysed by the xenobiotic enzyme CYP2F2 [12]. In adult mice, expression of CYP2F2 appears to be strictly limited to nonciliated airway epithelial cells [11]. Since both $\Delta$ N23KGF and NA had significant effects on the number of Clara cells per distal airway, as shown above, the fact that a decrease in Clara cell numbers per airway could simulate a decrease in CYP2F2 mRNA expression relative to that of GAPDH had to be taken into account. Therefore, the expression of CYP2F2 mRNA was related to that of CC10, which is highly specific for Clara cells [49]. Despite the slight reduction in CC10 mRNA expression in lungs pre-treated with $\Delta \mathrm{N} 23-\mathrm{KGF}, \Delta \mathrm{N} 23-\mathrm{KGF}$ reduced CYP2F2 mRNA expression to $\leqslant 25 \%$ of that of vehicle controls. Correspondingly, the present in vitro study of Clara cell-enriched lung epithelial cells isolated from C57BL/ 6 mice revealed a significant reduction in CYP2F2 mRNA expression in cells cultured for $4 \mathrm{~h}$ in the presence of $\Delta \mathrm{N} 23-K G F$. Notably, a population of CC10-positive variant Clara cells, which are maintained within neuroepithelial bodies, was demonstrated to be resistant to NA-induced injury due to low CYP2F2 expression [39]. This subpopulation of Clara cells with low CYP2F2 expression was suggested to be critical to the renewal of proximal airway epithelium following NA-induced injury [50]. A similar NA-resistant Clara cell subpopulation was located to the bronchiolar-alveolar duct junction and exhibited a number of features characteristic of region-specific endogenous stem cells [39]. These data suggest that a reduction in the expression of CYP2F2 mediated by $\Delta$ N23-KGF pre-treatment is able to significantly limit the Clara cell cytotoxicity of NA.

The failure of $\Delta \mathrm{N} 23-\mathrm{KGF}$ to ameliorate NA-induced injury when applied $24 \mathrm{~h}$ after NA-injection, i.e. at a time-point at which Clara cells are almost completely lost from the distal airway epithelium [41, 42], whereas Clara cell loss was significantly reduced by treatment with $\triangle \mathrm{N} 23-\mathrm{KGF} 2 \mathrm{~h}$ after injection of NA, demonstrates that the protective effect of $\Delta \mathrm{N} 23-\mathrm{KGF}$ is primarily related to Clara cells. This is in line with previous findings that the proliferative effect of KGF is restricted to Clara cells in rat distal airway epithelium [17].

As reviewed recently, NA is used as feedstock in various chemical industrial processes and is suggested to pose a problem in the workplaces of various industries [6, 7]. Hence it is conceivable that therapeutic application of $\Delta \mathrm{N} 23-\mathrm{KGF}$ immediately following accidental occupational exposure to high levels of NA might help to limit the development of severe airway epithelial injury, although additional studies in humans are required before such an approach can be translated into clinics.

In summary, it has been demonstrated that pre-treatment of lungs with N-terminally truncated recombinant human keratinocyte growth factor significantly reduced the naphthaleneinduced loss of Clara cells by necrosis and prevented the deterioration of respiratory function associated with airway injury. The present in vivo and in vitro findings suggest that the protective effect of $\mathrm{N}$-terminally truncated recombinant human keratinocyte growth factor is mediated, at least in part, by marked downregulation of the expression of cytochrome $\mathrm{P}_{450}$ isoform 2F2, the xenobiotic enzyme responsible for the metabolism of naphthalene into its cytotoxic intermediate. The success of a therapeutic application of N-terminally truncated recombinant human keratinocyte growth factor depends upon the presence of Clara cells.

\section{ACKNOWLEDGEMENTS}

The authors acknowledge the help of G. John (Dept of Pulmonary Medicine, Philipps University of Marburg, Marburg, Germany) with the cell culture model and for use of laboratory equipment.

\section{REFERENCES}

1 Puchelle E, Zahm JM, Tournier JM, Coraux C. Airway epithelial repair, regeneration, and remodeling after injury in chronic obstructive pulmonary disease. Proc Am Thorac Soc 2006; 3: 726-733.

2 Gauderman WJ, Avol E, Gilliland F, et al. The effect of air pollution on lung development from 10 to 18 years of age. N Engl J Med 2004; 351: 1057-1067.

3 Leikauf GD. Hazardous air pollutants and asthma. Environ Health Perspect 2002; 110: 505-526.

4 Plopper CG, Hyde DM. Epithelial cells of bronchioles. In: Parent RA., ed. Comparative Biology of the Normal Lung. Boca Raton, CRC Press, 1992; pp. 85-92.

5 Plopper CG, Van Winkle LS, Fanucchi MV, et al. Early events in naphthalene-induced acute Clara cell toxicity. II. 
Comparison of glutathione depletion and histopathology by airway location. Am J Respir Cell Mol Biol 2001; 24: 272-281.

6 Preuss R, Angerer J, Drexler H. Naphthalene - an environmental and occupational toxicant. Int Arch Occup Environ Health 2003; 76: 556-576.

7 Preuss R, Drexler H, Bottcher M, Wilhelm M, Bruning T, Angerer J. Current external and internal exposure to naphthalene of workers occupationally exposed to polycyclic aromatic hydrocarbons in different industries. Int Arch Occup Environ Health 2005; 78: 355-362.

8 Witschi H, Espiritu I, Maronpot RR, Pinkerton KE, Jones AD. The carcinogenic potential of the gas phase of environmental tobacco smoke. Carcinogenesis 1997; 18: 2035-2042.

9 Van Winkle LS, Buckpitt AR, Nishio SJ, Isaac JM, Plopper CG. Cellular response in naphthalene-induced Clara cell injury and bronchiolar epithelial repair in mice. Am J Physiol 1995; 269: 800-818.

10 Massaro GD, Singh G, Mason R, Plopper CG, Malkinson AM, Gail DB. Biology of the Clara cell. Am J Physiol 1994; 266: L101-L106.

11 Fanucchi MV, Murphy ME, Buckpitt AR, Philpot RM, Plopper CG. Pulmonary cytochrome P450 monooxygenase and Clara cell differentiation in mice. Am J Respir Cell Mol Biol 1997; 17: 302-314.

12 Shultz MA, Choudary PV, Buckpitt AR. Role of murine cytochrome P-450 2F2 in metabolic activation of naphthalene and metabolism of other xenobiotics. J Pharmacol Exp Ther 1999; 290: 281-288.

13 Plopper CG, Macklin J, Nishio SJ, Hyde DM, Buckpitt AR. Relationship of cytochrome P-450 activity to Clara cell cytotoxicity. III. Morphometric comparison of changes in the epithelial populations of terminal bronchioles and lobar bronchi in mice, hamsters, and rats after parenteral administration of naphthalene. Lab Invest 1992; 67: 553-565.

14 Ware LB, Matthay MA. Keratinocyte and hepatocyte growth factors in the lung: roles in lung development, inflammation, and repair. Am J Physiol Lung Cell Mol Physiol 2002; 282: 924-940.

15 Finch PW, Cunha GR, Rubin JS, Wong J, Ron D. Pattern of keratinocyte growth factor and keratinocyte growth factor receptor expression during mouse fetal development suggests a role in mediating morphogenetic mesenchymal-epithelial interactions. Dev Dyn 1995; 203: 223-240.

16 Boardman KC, Aryal AM, Miller WM, Waters CM. Actin re-distribution in response to hydrogen peroxide in airway epithelial cells. J Cell Physiol 2004; 199: 57-66.

17 Fehrenbach H, Fehrenbach A, Pan T, Kasper M, Mason RJ. Keratinocyte growth factor-induced proliferation of rat airway epithelium is restricted to Clara cells in vivo. Eur Respir J 2002; 20: 1185-1197.

18 Savla U, Waters CM. Barrier function of airway epithelium: effects of radiation and protection by keratinocyte growth factor. Radiat Res 1998; 150: 195-203.

19 Chapman KE, Waters CM, Miller WM. Continuous exposure of airway epithelial cells to hydrogen peroxide: protection by KGF. J Cell Physiol 2002; 192: 71-80.

20 Tillie-Leblond I, Gosset P, Le Berre R, et al. Keratinocyte growth factor improves alterations of lung permeability and bronchial epithelium in allergic rats. Eur Respir J 2007; 30: 31-39.

21 Waters CM, Savla U. Keratinocyte growth factor accelerates wound closure in airway epithelium during cyclic mechanical strain. J Cell Physiol 1999; 181: 424-432.

22 Gomperts BN, Belperio JA, Fishbein MC, Keane MP, Burdick MD, Strieter RM. Keratinocyte growth factor improves repair in the injured tracheal epithelium. Am J Respir Cell Mol Biol 2007; 37: 48-56.

23 Prince LS, Karp PH, Moninger TO, Welsh MJ. KGF alters gene expression in human airway epithelia: potential regulation of the inflammatory response. Physiol Genomics 2001; 6: 81-89.

24 Ding X, Kaminsky LS. Human extrahepatic cytochromes P450: function in xenobiotic metabolism and tissueselective chemical toxicity in the respiratory and gastrointestinal tracts. Annu Rev Pharmacol Toxicol 2003; 43: 149-173.

25 Hsu E, Osslund T, Nybo R, et al. Enhanced stability of recombinant keratinocyte growth factor by mutagenesis. Protein Eng Des Sel 2006; 19: 147-153.

26 Van Winkle LS, Buckpitt AR, Plopper CG. Maintenance of differentiated murine Clara cells in microdissected airway cultures. Am J Respir Cell Mol Biol 1996; 14: 586-598.

27 Hoymann HG. Invasive and noninvasive lung function measurements in rodents. J Pharmacol Toxicol Methods 2007; 55: 16-26.

28 Ulrich K, Stern M, Goddard ME, et al. Keratinocyte growth factor therapy in murine oleic acid-induced acute lung injury. Am J Physiol Lung Cell Mol Physiol 2005; 288: L1179-L1192.

29 Van Winkle LS, Gunderson AD, Shimizu JA, Baker GL, Brown CD. Gender differences in naphthalene metabolism and naphthalene-induced acute lung injury. Am J Physiol Lung Cell Mol Physiol 2002; 282: L1122-L1134.

30 Hyde DM, Harkema JR, Tyler NK, Plopper CG. Designbased sampling and quantitation of the respiratory airways. Toxicol Pathol 2006; 34: 286-295.

31 Elizur A, Adair-Kirk TL, Kelley DG, Griffin GL, deMello DE, Senior RM. TNF- $\alpha$ from macrophages enhances LPSinduced Clara cell expression of keratinocyte-derived chemokine. Am J Respir Cell Mol Biol 2008; 38: 8-15.

32 Wegmann M, Fehrenbach A, Heimann $\mathrm{S}$, et al. $\mathrm{NO}_{2}$ induced airway inflammation is associated with progressive airflow limitation and development of emphysemalike lesions in C57BL/6 mice. Exp Toxicol Pathol 2005; 56: 341-350.

33 Klug J, Beier HM, Bernard A, et al. Uteroglobin/Clara cell 10-kDa family of proteins: nomenclature committee report. Ann NY Acad Sci 2000; 923: 348-354.

34 Yano T, Mason RJ, Pan T, Deterding RR, Nielsen LD, Shannon JM. KGF regulates pulmonary epithelial proliferation and surfactant protein gene expression in adult rat lung. Am J Physiol Lung Cell Mol Physiol 2000; 279: L1146-L1158.

35 Plopper CG, Suverkropp C, Morin D, Nishio S, Buckpitt A. Relationship of cytochrome P-450 activity to Clara cell cytotoxicity. I. Histopathologic comparison of the respiratory tract of mice, rats and hamsters after parenteral administration of naphthalene. J Pharmacol Exp Ther 1992; 261: 353-363. 
36 Van Winkle LS, Isaac JM, Plopper CG. Repair of naphthalene-injured microdissected airways in vitro. Am J Respir Cell Mol Biol 1996; 15: 1-8.

37 Stripp BR, Maxson K, Mera R, Singh G. Plasticity of airway cell proliferation and gene expression after acute naphthalene injury. Am J Physiol 1995; 269: L791-L799.

38 Reynolds SD, Giangreco A, Power JH, Stripp BR. Neuroepithelial bodies of pulmonary airways serve as a reservoir of progenitor cells capable of epithelial regeneration. Am J Pathol 2000; 156: 269-278.

39 Giangreco A, Reynolds SD, Stripp BR. Terminal bronchioles harbor a unique airway stem cell population that localizes to the bronchoalveolar duct junction. Am J Pathol 2002; 161: 173-182.

40 Park KS, Wells JM, Zorn AM, et al. Transdifferentiation of ciliated cells during repair of the respiratory epithelium. Am J Respir Cell Mol Biol 2006; 34: 151-157.

41 Lawson GW, Van Winkle LS, Toskala E, Senior RM, Parks WC, Plopper CG. Mouse strain modulates the role of the ciliated cell in acute tracheobronchial airway injurydistal airways. Am J Pathol 2002; 160: 315-327.

42 Rawlins EL, Ostrowski LE, Randell SH, Hogan BL. Lung development and repair: contribution of the ciliated lineage. Proc Natl Acad Sci USA 2007; 104: 410-417.

43 Postlethwait EM, Joad JP, Hyde DM, et al. Three-dimensional mapping of ozone-induced acute cytotoxicity in tracheobronchial airways of isolated perfused rat lung. Am J Respir Cell Mol Biol 2000; 22: 191-199.

44 Vijayaraghavan R, Schaper M, Thompson R, et al. Computer assisted recognition and quantitation of the effects of airborne chemicals acting at different areas of the respiratory tract in mice. Arch Toxicol 1994; 68: 490-499.

45 Glaab T, Hoymann HG, Hohlfeld JM, et al. Noninvasive measurement of midexpiratory flow indicates bronchoconstriction in allergic rats. J Appl Physiol 2002; 93: 1208-1214.

46 Glaab $\mathrm{T}$, Ziegert $\mathrm{M}$, Baelder $\mathrm{R}$, et al. Invasive versus noninvasive measurement of allergic and cholinergic airway responsiveness in mice. Respir Res 2005; 6: 139.

47 Hohlfeld JM, Hoymann HG, Tschernig T, Fehrenbach A, Krug N, Fehrenbach $H$. Keratinocyte growth factor transiently alters pulmonary function in rats. J Appl Physiol 2004; 96: 704-710.

48 Atkinson JJ, Toennies HM, Holmbeck K, Senior RM. Membrane type 1 matrix metalloproteinase is necessary for distal airway epithelial repair and keratinocyte growth factor receptor expression after acute injury. Am J Physiol Lung Cell Mol Physiol 2007; 293: L600-L610.

49 Singh G, Katyal SL. Clara cells and Clara cell 10 kD protein (CC10). Am J Respir Cell Mol Biol 1997; 17: 141-143.

50 Reynolds SD, Hong KU, Giangreco A, et al. Conditional Clara cell ablation reveals a self-renewing progenitor function of pulmonary neuroendocrine cells. Am J Physiol Lung Cell Mol Physiol 2000; 278: 1256-1263. 